\title{
DE LA FURIA COMO LUGAR EPISTÉMICO: LA FILOSOFÍA Y EL ARTE DE VANGUARDIA COMO FORMAS DE CRÍTICA A LA VIDA COTIDIANA
}

\section{Camilo Retana}

a Felipe Granados, in memoriam

\begin{abstract}
RESUMEN
En este artículo, pretendo problematizar el rol -sobredimensionado- que se le asigna en los aparatos teóricos clásicos a la racionalidad. Para ello, riño con el lugar común epistémico según el cual los sentidos enturbian los procesos cognitivos. En mi propuesta alternativa a esa epistemología desorientada, planteo la furia como categoría central. En el texto, argumento que dicha herramienta ético-epistémica, cuya procedencia es eminentemente emocional, no solo enturbiaría los procedimientos cognitivos sino que, por el contrario, los potenciaría (en particular los relacionados a la crítica de los sistemas morales hegemónicos). Como ejemplos de esta crítica al racionalismo y de esta apología de la furia traigo a colación algunas manifestaciones del arte vanguardista y algunas ideas filosóficas de pensadores no racionalistas.

Palabras clave: cotidianidad, arte de vanguardia, crítica social.
\end{abstract}

\begin{abstract}
In this article I intend to problematize the role-overdimensioned- that has been assigned in the classic theory to the rationality. For this I struggle with the common argument according to which the senses trouble the cognitive processes. In my alternative proposal to that epistemology I present the fury as main category. In the text I debate that such ethical-epistemic tool, which precedence is imminently emotional, would not only trouble the cognitive procedures but on the opposite would overpower them (particularly those related to the criticism of the hegemonic moral systems). As examples of this critic to the rationality and of this defense to the fury I present some manifestations of vanguards art and some philosophical ideas of non -rationalist philosophers.
\end{abstract}

Key words: quotidian, vanguard art, social criticism.

Lic. Camilo Retana. Profesor de la Escuela de Filosofía de la Universidad de Costa Rica. Correo electrónico: camiloretana@hotmail.com

Recepción: 5- 4- 2010

Aceptación: 8- 5- 2010 


\section{Sobre logofilia y metafísica}

Según cuenta la historia, Tales era capaz de predecir eclipses, pero incapaz de sortear los obstáculos que tenía bajo sus pies. Desde entonces la filosofía padece de una extraña invalidez: capaz de dar cuenta de las más depuradas abstracciones, deviene ejercicio inútil cuando de hablar del aquí y del ahora de trata. Por eso se ha destacado, y no en pocas ocasiones, la inutilidad de la filosofía. Marx hablaba de que la verdadera misión del pensamiento consistía en hacer que la crítica del cielo llegara a convertirse en crítica de la tierra. En otras palabras, a problemas metafísicos solo pueden ofrecerse respuestas metafísicas, y es por eso que, a partir de los devaneos supramundanos de la filosofía, se ha priorizado la construcción de sistemas de pensamiento caracterizados por una suerte de asepsia racionalista. Logofilia y metafísica forman así una sólida mancuerna a partir de la cual desaparecen del escenario a un tiempo lo cotidiano y lo irracional.

Y con ellos desaparece también la mierda. El kitsch, en tanto concepto que desborda lo meramente estético, se encuentra en el centro mismo de la filosofía. El pensamiento occidental conjura desde su génesis, y en un solo movimiento, todo lo feo, lo irracional, lo sucio y lo mundano. Quizá por eso Platón soñaba una república libre de fabuladores y poetas, donde el logos no se viera jamás amenazado por los delirios y las ensoñaciones de esos sujetos extravagantes. Los artistas y los locos, esas dos clases de hedonistas, poco dotados tanto para la sublimación como para la postergación de los deseos, ponen en crisis no solo la racionalidad como único criterio de ingreso al mundo, sino también la metafísica como tonalidad de dicho ingreso.

No obstante, así como en el ámbito del pensamiento podríamos rastrear un linaje maldito que reniega de ese proceder políticamente correcto de la filosofía, en el arte, podemos encontrar un conjunto de producciones estéticas que hacen parte de eso que Marx llama una "conciencia invertida del mundo". Es decir, también hay un arte que traspone los problemas de este mundo y que deja la realidad sin trastocar. Se trata del arte producido desde la oficialidad.

Pero este texto no versa sobre la filosofía y el arte que se alían con el poder, sino sobre ciertas manifestaciones artísticas y filosóficas contrahegemónicas y sobre las posibilidades que ellas abren a la hora de conocer el mundo de modo alternativo. Porque razonar no es en modo alguno la única vía para conocer.

\section{Sentir también es conocer}

El entronizamiento del logos como fuente cognitiva data de épocas remotas. Para el propio Platón, el mundo es cognoscible en virtud de nuestra facultad de pensar y por eso los sentidos son una especie de lastre molesto para la filosofía. Esta logofilia se asienta de manera aún más aguda en la modernidad (tanto artística como filosófica). Mientras Hegel afirma aquello de que "lo que es racional es real y lo que es real es racional" (2000, p. 74) y Kant apuesta a lo interno de su sistema filosófico por la razón pura, Descartes, por su parte, señala que la voluntad es la fuente única de error y, por ende, la enemiga por excelencia de la racionalidad.

¿De dónde nacen, pues mis errores? Solo de esto: que, siendo la voluntad más amplia que el entendimiento, no la contengo dentro de los límites que éste, sino que la extiendo también a las cosas que no entiendo, y, siendo indiferentes a estas, se extravía con facilidad, y escoge el mal en vez del bien, o lo falso en vez de lo verdadero. Y ello hace que me engañe y peque. (Descartes 2009: 21) 
Aunque Descartes condena los sentidos y ensalza una razón divorciada de lo concreto, reconoce que la voluntad es capaz de llegar allí donde no llega el entendimiento. No obstante, a pesar de la potencia epistemológica que contendrían los sentidos para el pensador francés, estos deben ser objeto de desprecio filosófico. Es contra este tipo de filosofía que arremete Nietzsche (filósofo que, dicho sea de paso, tuvo una influencia notable en los planteamientos teóricos de las vanguardias artísticas de la modernidad). Para él, lo que existe es lo que se nos aparece, por lo que no hay permanencia alguna detrás del cambio. Para el filósofo alemán, no obstante, detrás de ese rechazo unilateral de los sentidos hay otro rechazo primigenio. Se trata del desprecio del cuerpo. La esfera de lo sintiente queda usualmente reducida en los aparatos epistemológicos clásicos a fuente de error. En palabras de Nietzsche, la prerrogativa de este tipo de filosofías es:

\footnotetext{
Rechazar todo lo que confirme los sentidos y con ello a la humanidad. Es vulgar. Hay que ser filósofo momia y representar un acto de monoteísmo con gestos de sepulturero. Hay que rechazar básicamente el cuerpo, que es una aborrecible idea fija de los sentidos, carente de lógica, rechazado, jaunque sea tan impertinente como para portarse como si fuera algo real! (2004: 44-45)
}

Pero no solo desde filosofías contestatarias como la de Nietzsche se realizan críticas a esta apuesta racionalista por un logos abstraído de lo sensitivo. Las vanguardias artísticas de la modernidad también se levantan contra esa marginación de lo sintiente que, valga insistir en ello, tiene una versión artística en las vertientes estéticas de corte mimético. El arte vanguardista, en tanto contrapunto negativo de las visiones de mundo canónicas del Occidente moderno, la embiste contra ese arte y esa epistemología sordos para con lo subjetivo/sensitivo. El vanguardista ruso Malévich, por ejemplo, escribe:

\footnotetext{
La ascensión a las alturas del arte no objetivo es fatigosa y llena de tormentos y, sin embargo, nos hace felices. Los contornos de la objetividad se hunden cada vez más a cada paso y, al fin, el mundo de los conceptos objetivos, "todo lo que habíamos amado y de lo que habíamos vivido", se vuelve invisible. Ya no hay "imágenes de la realidad”; ya no hay representaciones ideales; ¡no queda más que un desierto! Pero ese desierto está lleno del espíritu de la sensibilidad no-objetiva, que todo lo penetra. (De Micheli 1984: 386-387)
}

Este distanciamiento con la objetividad tiene lugar desde el hedonismo característico de las vanguardias, las cuales, al igual que ciertos pensadores inscritos en líneas como la genealogía crítica, el marxismo o la fenomenológica, se caracterizan por su reivindicación de la cotidianidad. La filosofía y el arte aparecen así como instrumentos capaces de catapultar tanto una razón que se abstrae de lo sensitivo y con ello de lo cotidiano, como de enarbolar una sensibilidad anclada en lo sintiente.

\section{La furia como categoría epistemológica}

El racionalismo europeo recomienda purgar la razón de todo enturbamiento pasional. El pensador debe poner entre paréntesis su universo pulsional, de modo que sus constructos teóricos estén provistos de rigurosidad lógica. El artista, por otra parte, debe apelar de manera constante a una sola estética que lo distinga y de ese modo lo posicione en el mercado (debe, por lo demás, tener el cuidado de ser entendido). Es el mundo del cálculo y la simetría, de la armonía y la estabilidad. En una palabra, se trataría de un arte y una epistemología regidos por la permanencia y la previsibilidad.

Pero existe una modernidad subterránea que se ha encargado de poner en crisis toda esta asepsia de la ilustración racionalista. Un hito en estas tendencias contrailustradas es el 
pensamiento de Sigmund Freud ${ }^{1}$. Para Freud, el ser humano no se agota en su dimensión racional, por lo que cualquier consideración sobre el mismo como un ser exclusivamente racional es incompleta. Y si bien la epistemología freudiana tiene pretensiones científicas, hay que decir que ciertas intuiciones y correlaciones establecidas por el padre del psicoanálisis tienen mucho más de corazonada que de lógica. Este impulso tendiente a la superación del binarismo propio de la lógica formal es precisamente el que despierta la irritación de positivistas como Mario Bunge, quien califica al psicoanálisis de pseudociencia, precisamente por cuanto combina recursos intuitivos con argumentos lógicos.

Por su parte, aunque en el ámbito del arte, las vanguardias recogen buena parte de estos planteamientos freudianos antiracionalistas. En especial los dadaístas, pero sobre todo los surrealistas, crean un conjunto de producciones estéticas que, tanto a nivel de forma como a nivel de contenido, se distancian de los ideales de la razón (simetría en la composición, buen gusto, mimesis, etc.).

El apego a la lógica en el ámbito teórico y a la uniformidad estética en el campo artístico tienen en común su adhesión a lo sistémico. Es por eso que existe tanto en las vanguardias como en las filosofías radicales un rechazo al pensamiento totalizante. Al respecto escribe Tristán Tzara: “odio la objetividad grasa y la armonía, esa ciencia que encuentra que todo está en orden [...]. Estoy contra los sistemas, el más aceptable de los sistemas es no tener, por principio, ninguno"(1987: 20).

Pero una vez rechazadas la logicidad y la sistematicidad ¿qué rumbos epistemológicos tomar? Para responder a esta pregunta quisiera proponer como lugar epistemológico alternativo a la razón, una categoría usualmente despreciada desde las teorías del conocimiento logicistas. Hablo de la furia ${ }^{2}$.

La furia, como parte de esas herramientas epistémicas exiliadas por la razón, aparece como un recurso maldito tanto dentro de la filosofía oficial (donde lo pasional entorpece al sujeto filosofante) como dentro del arte oficial (donde las musas no tienen nada de furiosas) ${ }^{3}$. En este sentido, la furia es un concepto no solo con alcances epistemológicos, sino también políticos, éticos y estéticos. En el dadaísmo, por ejemplo, el gesto fúrico, constitutivo tanto del arte Dadá como de sus planteamientos políticos, está íntimamente entrelazado con sus posturas epistemológicas antilogicistas:

\footnotetext{
Nos hacen falta obras fuertes, rectas, precisas e incomprendidas para siempre. La lógica es una complicación. La lógica siempre es falsa. Ella tira de los hilos de las nociones, palabras, en su exterior formal, hacia objetivos y centros ilusorios. [...] Casado con la lógica, el arte viviría en el incesto, engullendo, tragándose su propia cola siempre su cuerpo, fornicándose en sí mismo, y el genio se volvería una pesadilla asfaltada del protestantismo, un monumento, una pila de intestinos grisáceos y pesados" (Tzara 1987: 22)
}

Lo que en las vanguardias en general, y en Dadá en particular es una postura conscientemente asumida, es en muchas producciones, tanto estéticas como teóricas, un componente que opera tan inevitable como subrepticiamente; pues toda forma de aproximación al mundo supone una carga subjetiva. Solo una concepción metafísica del sujeto filosofante que ve en este un ser carente de voluntad y desprovisto de pasiones podría creer lo contrario. En otras palabras: el perspectivismo es ineludible. La supuesta neutralidad moral del sujeto epistémico clásico y su supuesto apolitismo desembocan así en el peor de los conservadurismos: el que se disfraza de objetividad. En su búsqueda de verdades metafísicas, la filosofía oficial tiene como combustible el mero afán abstracto de saber (en la versión naif del platonismo es el asombro el que nos lleva a querer conocer). Pero hay que decir que, en realidad, todo proceso cognitivo requiere involucrar al cuerpo. Y es allí donde aparece la furia. 
El artista y el filósofo furibundos producen un conocimiento encarnado. El anclaje corporal de ese conocimiento tiene una doble veta. Por un lado, es un conocimiento que parte de una reacción corpórea hacia la podredumbre social (en este sentido se trata de una episteme que se construye desde el cuerpo); por el otro, se trata de un saber que busca ya no una libertad racional abstracta, sino una liberación de carácter orgánico (en este sentido, se trata de una episteme que se construye para el cuerpo). Como ejemplo de pensadores inscritos en esta línea, podemos mencionar, entre otros, a autores como Michel Foucault, Marx, MerleauPonty, Nietzsche, Benjamín, Marcuse y Lukács. Como ejemplos de arte fúrico podemos destacar movimientos vanguardistas como el surrealismo, el dadaísmo y ciertas tendencias del futurismo ruso.

La furia como motor cognitivo, como zarpazo al ojo erudito. La furia como criterio ético y como posicionamiento moral; como daga al pensamiento positivo, a la floritura. En fin, la furia como estética, como gestualidad, como afrenta a una cotidianidad enajenada y estructurada desde una racionalidad del olvido y el confort.

\section{La mentira tiene efectos de verdad}

Una epistemología de la furia asigna un lugar enteramente novedoso al tema de la verdad. La teoría de la correspondencia afirma que hay verdad cuando lo pensado coincide con la representación mental que se hace de ello. Otro tanto sucede en el arte mimético: tanto mejor realizada está una obra cuanto más se apega a aquello que intenta retratar. En ambos casos, lo imaginativo queda en un segundo plano frente a la exigencia de hacer coincidir ya sea la idea, o la obra, con "lo real" (cualquier cosa que eso signifique). Pero, para un sujeto que aspira a conocer y transformar el mundo de forma furibunda, el mundo es algo por destruir y la verdad y la belleza son solamente obstáculos para esa destrucción. La lógica intenta preservar el mundo, contentándose con describirlo; el arte políticamente correcto intenta preservar el mundo, embelleciéndolo. Pero "solo los ingenuos creerían posible que el mundo, que según el verso de Baudelaire ha perdido su aroma y sus colores, recuperara [ese aroma y esos colores] desde el arte" (Adorno 1971: 60). Otro tanto podríamos decir de los intentos de la ciencia y la filosofía por blanquear lo oscuro ${ }^{4}$.

Cuando los historiadores eruditos, que comentaban sus primeras obras, reclamaban a Foucault, que su Historia de la locura estaba plagada de imprecisiones históricas y de hipótesis sin ningún asidero empírico, el filósofo replicaba que la mentira tiene efectos de verdad. Una epistemología de la furia pone su acento precisamente en el impacto que una tesis puede llegar a tener antes que en la veracidad de dicha tesis. "No digo cosas porque las piense" llega incluso a decir Foucault: "las digo, más bien, con un propósito de autodestrucción" (citado por Miller 1995: 323).

Las vanguardias, por su parte, comparten ese modus operandi. Como parte de su temple antitético, estos movimientos de artistas no solo rechazan todo proceder afirmativo, sino que se asientan en la negación. En este sentido, lo falso es algo más que un momento que posibilita la consecución de una verdad ulterior. La no-objetividad del suprematismo ruso, la a-logicidad de los dadaístas -Dadá dice: "si cada quien dice lo contrario es porque tiene razón" (Tzara 1987: 28) - y la insistencia del futurismo en el movimiento (en contraposición a una plástica y una literatura realistas y anquilosadas, salvaguardias de lo inmóvil) dan cuenta de cómo las vanguardias están más interesadas en destrozar la realidad que en reproducirla. Este 
temperamento devastador (¡incluso el arte merece ser exterminado!) llega a su culmen en el surrealismo, donde la distorsión de lo real, tiene que ver más con un intento de reconfiguración de lo percibido que con su emulación. Según Bretón, "quizá haya llegado el momento en que la imaginación esté próxima a ejercer los derechos que le corresponden" (citado en González 2003: 394). El surrealismo reniega no solo del realismo, sino de la obsesión del pensamiento por organizar racionalmente el mundo. De ahí que el componente onírico/imaginativo, y su carácter metaracionalista, tuviera a la postre un papel preponderante en el surrealismo.

Como los sueños, la realidad está plagada de ambigüedad. El concepto de verdad no es más que un intento de despojar el mundo de esa ambivalencia. Si el norte del conocimiento es transformar, entonces hemos de reconocer que en la mentira hay también una dimensión cognitiva, en la medida en que el acto de enunciar lo falso tiene una capacidad de incidencia -destructiva- en el tejido social.

\section{Filosofía, arte y vida cotidiana}

Esta capacidad destructiva de la filosofía y el arte negativos convergen en su crítica de la vida cotidiana. De nuevo, la mentira cobra aquí un papel especial: en lugar de aspirar a mostrar o enunciar, ya sea desde el arte o el pensamiento, una supuesta verdad, las vanguardias y la filosofía crítica muestran el anverso de la positividad. Lo que en la cotidianidad es ocultado o bien sencillamente negado (en una palabra, lo que desde la sensibilidad dominante es pensado como falso), es de-velado en esa misma cotidianidad mediante el gesto de denuncia. Pero ese develamiento no es considerado la revelación de una verdad, sino una farsa; una broma que corroe. De ahí que las vanguardias se abstengan de proponer una moralidad con contenido positivo y se afiancen en lo anti(t)ético: "yo hago lo contrario de lo que propongo a los demás" (1987: 35), señala Tristán Tzara, el bufón dadaísta.

Ese acto rebosante de furia que enuncia lo falso rechaza vehementemente todo ethos que no se ancle en la cotidianidad presente. Los propios futuristas proclaman en uno de sus manifiestos: "Dejemos el pasado a nuestras espaldas como una carroña. Dejemos el futuro a los profetas. Nosotros nos quedamos con el hoy" (Naum Gabo y Antoine Pevsner citados en De Micheli 1984: 402).

La relación de las vanguardias con la historia es compleja y variopinta ${ }^{5}$. No obstante, la casi totalidad de estos movimientos suscriben un tipo de historiografía que desemboca en una praxis crítica transformadora de lo cotidiano. La relación tirante de las vanguardias con las distintas agrupaciones y partidos de izquierda se explica en buena medida por el énfasis que estas ponen en la transformación de la cotidianidad, frente a un marxismo ortodoxo de tono más bien profético, interesado unilateralmente en el futuro. El neomarxismo comparte con las vanguardias ese interés en pensar la libertad como una producción continua que se da en el día a día. Son los marxistas con influencia hegeliana, de hecho, los que perfilan eso que se ha dado en llamar filosofía de lo cotidiano. Autores como Lefebvre, Agnes Heller, Benjamin y Kosik señalan los riesgos que comporta para el pensamiento fijar la atención unilateralmente en el futuro o el pasado sin tensionarlos suficientemente con el presente ${ }^{6}$. Lo cotidiano aparece así como un lugar central de lo político, más allá de la comprensión de la historia que presta atención únicamente al hecho extraordinario. Así, los filósofos de lo cotidiano invierten el esquema analítico clásico y dan al presente un protagonismo inusitado: " The most extraordinary things are also the most everyday; the strangest things are often the most trivial" 7 
Particular afinidad hay entre la filosofía de lo cotidiano y la crítica de algunas vanguardias europeas al tema del progreso. Mientras para Benjamín la cultura humana se erige sobre los escombros que va dejando a su paso, los artistas vaguardistas europeos se declaran, casi de forma unánime, en contra de una comprensión evolutiva de la historia del arte. La idea del progreso, tanto en el arte como en la política, termina siendo una legitimación de la posición metafísica según la cual la historia tiene una vida propia y, por lo tanto, no son los seres humanos los que dominan el destino de las sociedades. El rechazo de la cotidianidad, supone, pues, a un tiempo, renegar del ser humano encarnado y con necesidades presentes y concretas y traslapar la necesidad de generar cambios ahora, y no en el futuro.

\section{Epílogo}

Toda labor, tanto epistemológica como artística, involucra al sujeto en su totalidad. Así, en los esfuerzos por conocer y transformar el mundo que habita cotidianamente, el ser humano implica su razón y su cuerpo, sus temores y anhelos, pues le va la vida en ello. El arte y el pensamiento, si no quiere producirse de espaldas al mundo, requieren romper cierto espesor. Y ese espesor no se vence si no a través de la furia.

\section{Notas}

1. Me parece claro el hecho de que Freud es una especie de crisol de la Modernidad, en el que coexisten, a un tiempo, rasgos del pensamiento ilustrado y elementos que contravienen esa tradición. El carácter ilustrado de su psicología se evidencia en sus tesis clínicas, en las que se plantea a menudo que la racionalización de procesos inconscientes es curativa. Su enfoque contrailustrado se evidencia, paradójicamente, en su reconocimiento del inconsciente y en el papel determinante que asigna a este en la vida libidinal del sujeto

2. El pensamiento latinoamericano ha visto en el arte uno de sus principales medios de expresión. Los componentes filosóficos de la literatura borgiana o cortazariana, por ejemplo, dan cuenta de ello, por no hablar del aporte filósofico-literario de autores como Roque Dalton, José Martí o Ernesto Cardenal. En el ámbito musical, la furia como categoría metalógica con alcances poético - epistémicos ha sido utilizada por la banda argentina Soda Stereo en su canción En la ciudad de la furia: "Me verás volar/ Por la ciudad de la furia / Donde nadie sabe de mí/ Y yo soy parte de todos/ Nada cambiará / Con un aviso de curva/ En sus caras veo el temor/ Ya no hay fabulas/ En la ciudad de la furia./ Me verás caer/ Como un ave de presa/ Me verás caer/ Sobre terrazas desiertas/ Te desnudaré/ Por las calles azules/ Me refugiaré/ Antes que todos despierten/ Me dejarás dormir al amanecer/ Entre tus piernas/ Entre tus piernas/ Sabrás ocultarme bien y desaparecer/ Entre la niebla/ Entre la niebla/ Un hombre alado extraña la tierra/ Me verás volar/ Por la ciudad de la furia/ Donde nadie sabe de mi/ Y yo soy parte de todos/ Con la luz del sol/ Se derriten mis alas/ Solo encuentro en la oscuridad/ Lo que me une con la ciudad de la furia/ Me verás caer/ Como una flecha salvaje/ Me verás caer/ Entre vuelos fugaces/ Buenos Aires se ve tan susceptible/ Ese destino de furia es/ Lo que en sus caras persiste/ Me dejarás dormir al amanecer/ Entre tus piernas/ Entre tus piernas/ Sabrás ocultarme bien y desaparecer/ Entre la niebla/ Entre la niebla/ Un hombre alado prefiere la noche/ Me verás volver/ Me verás volver/ A la ciudad de la furia” (Sony Music 1988).

3. La musa es una figura asociada al, tan denostado por las vanguardias, arte aurático. Un joven poeta dominicano, Frank Báez, heredero a todas luces de la estética vanguardista, escribe sobre este tema en su poema Peleas Domésticas, lo siguiente: "Mientras escribo en el papel/ a las tres de la mañana/ una musa me escupe la cara/ otra musa me grita/ una me trae vodka/ y me susurra no escribas/ me trae drogas/ me trae modelos de revistas/ no escribas no escribas/ repiten al unísono/ día y noche/ noche y día" (2008: 41) 
4. Autores como Adorno y Baudrillard reivindican en este sentido lo negro y el mal como esferas fundamentales en los ámbitos estético y moral

5. Los futuristas italianos, por ejemplo, se posicionan frente a la historia de manera un tanto mesiánica, mientras que el futurismo ruso y las vanguardias latinoamericanas, si bien poseen algunos componentes de carácter utópico, ponen un fuerte énfasis en la militancia partidaria y con ello en la transformación del presente social. El dadaísmo es quizá la vanguardia con un tinte más distópico al tiempo que el surrealismo tiende a comprender la historia en clave marxista

6. Para Kosik “' [e]l futuro es en fin de cuentas una fuga enajenada de la enajenación, esto es, una superación ilusoria de la enajenación. 'Vivir en el futuro' y 'anticiparse' es, en cierto sentido, la negación de la vida: el individuo como ocupación no vive el presente, sino el futuro, y desde el momento en que niega lo que existe y anticipa lo que no existe, su vida se reduce a cero, es decir, a la inautenticidad" (1967: 47). En contrapartida, la nostalgia por el pasado ha mostrado ser una aliada del conservadurismo, toda vez que a partir de la idealización de lo antiguo se crea un clima de animadversión al cambio

7. "Las cosas más extraordinarias son también las más cotidianas; las más extrañas cosas son a menudo las más triviales" (Lefebvre 2008: 13, traducción propia)

\section{Bibliografía}

Adorno, T.W. 1971. Teoría estética (Trad. Fernando Riaza). Madrid: Taurus.

Báez, F. 2008. Postales. San José: EUCR.

Descartes, R. 2009. Meditaciones metafísicas. http://www.quedelibros.com. Consulta: 17 de octubre, 2009.

De Micheli, M. 1984. Las vanguardias artísticas del siglo XX. (Trad. Angel Sánchez Girón). Madrid: Alianza.

Gonzáles G. A. et al (comp.). 2003. Escritos de arte de vanguardia.1900/1945. Madrid: Istmo.

Hegel, G.W.F. 2000. Rasgos fundamentales de la filosofía del derecho (Trad. Eduardo Vásquez). Madrid:Falta el nombre de la editorial.

Kosik, K. 1967. Dialéctica de lo concreto. Estudio sobre los problemas del hombre y el mundo (Trad. Adolfo Sánchez Vazquez). México: Grijalbo.

Lefebvre, H. 2008. Critique of every day life (Trad. J. Moore, G. Elliot). EUA: Verso.

Marx, K. 1973. Contribución a la crítica de la filosofía del derecho de Hegel. En K. Marx\& A. Ruge, 101-106

Marx, K \& A. Ruge. 1973. Los anales franco alemanes (2 ed.). Barcelona: Martínez Roca. 
Merleau-Ponty, M. 2000. Fenomenología de la percepción (Trad. Jem Cabanes). Barcelona: Península.

Miller, J. 1995. La pasión de Michel Foucault. Argentina: Editorial Andrés Bello.

Nietzsche, F. 2004. Cómo se filosofa a martillazos (Trad. Susana Aguiar). Madrid: Alianza.

Soda Stereo. 1988. En la ciudad de la furia. Buenos Aires: Sony Music.

Tzara, T. 1987. Siete manifiestos Dadá (Trad. Huberto Haltter). Barcelona: Tusquets. 